\title{
DEVELOPMENT AND VALIDATION OF THE ACCULTURATIVE HASSLES SCALE FOR CHINESE STUDENTS (AHSCS): AN EXAMPLE OF MAINLAND CHINESE UNIVERSITY STUDENTS IN HONG KONG
}

\author{
Jia-Yan PAN'), Xiaodong YUE ${ }^{2)}$, and Cecilia L. W. CHAN ${ }^{1)}$ \\ ${ }^{1)}$ The University of Hong Kong, China, ${ }^{2)}$ City University of Hong Kong, China
}

\begin{abstract}
The development and initial validation of a 17-item Acculturative Hassles Scale for Chinese Students (AHSCS) is described. Items were generated by in-depth interview, selected by item analysis, and validated in a sample of 400 Chinese mainland students in Hong Kong. Factor analysis suggested four factors with 17 items: Language Deficiency, Academic Work, Cultural Difference, and Social Interaction. Scores in this study showed satisfactory internal consistency reliability for the AHSCS and its four subscales. The AHSCS score shows a statistically significant positive correlation with negative affect and significant negative correlations with positive affect and life satisfaction. These results suggest that the AHSCS appears to be a reliable and valid instrument to measure acculturative stressors within a Chinese student population. However, further validation of the scale is still needed.
\end{abstract}

Key words: acculturative stress, cross-cultural adaptation, Chinese student

As an overseas colony of the British government for over 150 years, Hong Kong has a long history of being a society that receives migrants from mainland China (Lam \& Liu, 1993). Since its handover to China in 1997, Hong Kong has attracted more and more mainland students to pursue advanced education. The number of newly-admitted mainland students to Hong Kong universities has tripled in the past decade (University Grants Committee in Hong Kong, 2008). The majority of mainland students are postgraduate students who are studying for their $\mathrm{PhD}$ or MPhil degree in Hong Kong. Hong Kong universities regard mainland China as a fertile ground to recruit students, and these students are expanding the region's academic influence (Jiang, 2002). An understanding of the psychological adaptation of mainland Chinese students would enable the host education and service providers to offer better and more appropriate services for these students.

Acculturation is the process of change that occurs to a person in a cross-cultural situation, both by the influence of contact with another culture and the culture of origin (Berry, 1990). Mainland students experience a process of acculturation in Hong Kong because of the cultural differences between Hong Kong and mainland China (ITIMInternational, 2003a, 2003b), and the acculturative stress experienced by mainland migrants in Hong Kong (Chan, 2002).

This study was supported by a 2005 Wu Jieh-Yee Research Fund from The University of Hong Kong.

Correspondence concerning this article should be addressed to Dr. Jia-Yan PAN, Department of Social Work, The Chinese University of Hong Kong, Shatin, N.T. , Hong Kong, People's Republic of China (e-mail: jiayan2004@msn.com). 


\section{Conceptualization of Stress and Acculturative Stress}

The conceptualization of stress is controversial in stress literature. The stimulusbased approach defines stress as any event or environmental stimulus that is perceived as demanding or threatening to the individual (Cox, 1978). The response-based approach defines stress as psychological and physiological response to events or stimulus in a demanding environment (Selye, 1982; Cox, 1978). These two approaches fail to take the individual differences into consideration, and equate stress with a stressor or the outcomes of stress. In contrast, the interactional approach defines stress as an interaction between the environment and the individual (Aldwin, 1994), which results from an imbalance between the perceived environmental demand and a person's perception of his or her capacity to meet that demand (Cox, 1978). In the most influential transactional model of stress, Lazarus and Folkman (1984) treat stress as an interdependent process of the interplay between the stressor (environmental and/or internal demand), intervening factors (personal and/or environmental resources), and stress reaction (physical and/or psychological well-being). As a "micro-stressor", hassles are "the irritating, frustrating, distressing demands that to some degree characterize everyday transactions with the environment" (Kanner, Coyne, Schaefer, \& Lazarus, 1981, p. 3). Daily hassles have been well documented to be good predictors of both psychological and physical outcomes (Kanner et al., 1981; Rowlison \& Felner, 1988). Thus, the measure of hassles would enhance our understanding of the stressor-outcome relationship and their impact on physical and mental health.

Acculturative stress is inherent in the process of adaptation to a new culture (Perez, Voelz, Pettit, \& Joiner, 2002). Similarly, three approaches have been proposed to conceptualize acculturative stress. The stimulus-based approach defines acculturative stress as the conflicts, difficulties or stressors arising from the cross-cultural adaptation (Joiner Jr \& Walker, 2002). In contrast, the response-based approach regards acculturative stress as a "reduction in the health status of individuals confronting the problems of cultural change" (Mishra, Sinha, \& Berry, 1996, p. 233). The process-oriented approach defines acculturative stress as an interaction process between acculturating individuals and the new environment of the host society, and takes personal appraisal and coping into consideration (Shuval, 1982). In Berry's (2006a, 2006b) model, acculturative stress is a process of interaction between acculturative stressor, cognitive appraisal and coping, and adaptation outcomes. Acculturative hassles are the daily hassles encountered specific to the migration status in the context of acculturation (Lay \& Nguyen, 1998). The measurement of acculturative hassles experienced by various groups of migrants in crosscultural adaptation seems to have significant importance in acculturation research.

\section{Acculturative Stressors Experienced by Chinese International Students}

Acculturating to a new culture is a stressful life experience for most migrants. Chinese international students in English-speaking countries may encounter various acculturative stressors in five domains. The first concerns language-related issues, such as difficulties in listening to and speaking English (Xu, 2002); difficulties in understanding slang, jokes, idioms, common vocabulary, and topics of conversation (Sheh, 1994); and a 
lack of confidence in using English in daily life (Swager \& Ellis, 2003). The second relates to academic issues in course work, research, and teaching assistance ( $\mathrm{Lu}, 1998)$, such as difficulties in participating in class discussions (Mak \& Barker, 2006), making oral presentations, and taking exams (Ward \& Masgoret, 2004); different classroom communication styles and interactions from those of their country of origin (Ho, Holmes, \& Cooper, 2004); and few changes in the curriculum within a multicultural classroom (Ward, 2006a). The third domain comprises psycho-social-cultural issues, such as a lack of social support networks (Williams, 2003); a low frequency of social interaction with domestic students (Ward, 2006a); difficulties in intercultural communication (Kim, 2005), racial discrimination (Ward, 2006b) and social non-acceptance (Sobrun-Maharaj, 2006); homesickness ( $\mathrm{Lu}, 1990)$ and loneliness (Hsu, Hailey, \& Range, 1987). The fourth includes the financial issues involved in supporting overseas study and living, such as competition for financial assistantships ( $\mathrm{Lu}, 1998)$ and having to share financial aid with a spouse or children (Lin, 1998). The fifth includes all other issues, such as political concerns (Sun \& Chen, 1997); lack of information about services and facilities (Ward \& Masgoret, 2004); and concerns about food, health, housing, transportation, security, religion, and tax (Lin, 1998).

\section{Acculturative Stressors Experienced by Mainland Immigrant Students in Hong Kong}

Chan (2002) summarized two common adaptation problems experienced by mainland immigrant students in Hong Kong from five local studies (Hong Kong Federation of Youth Groups, 1995, 1997; Chan, Ip, \& Yuen, 1997; Chan \& Ma, 1999; Lo, Wan, \& Chung, 1998): academic adaptation and social adaptation. Academic adaptation includes learning difficulties in subjects because of the lack of language proficiency in English and Cantonese (Chan, 1999; Lo et al., 1998). Social adaptation is concerned with issues such as establishing peer relationships in a new environment (Chan et al., 1997; Hong Kong Federation of Youth Groups, 1997), a lack of family support systems (Chan \& Ma, 1999), and unfamiliarity with community resources and network (Hong Kong Federation of Youth Groups, 1995).

In addition, mainland students experience identity confusion and rejection of individualism arising from cultural conflicts (Fung, 2000). Wong (1997) identified other four categories of acculturative difficulties for mainland immigrant students in Hong Kong: survival issues, losses, cultural differences, and unfulfilled expectations. Moreover, life satisfaction and future life expectations (Chan \& Ma, 1999), acceptance of a new housing type (Hong Kong Federation of Youth Groups, 1997), family life and leisure activity (Lee \& Chen, 2005), and integration into Hong Kong society (林静雯, 2000) were found to be adjustment difficulties faced by new arrival students from mainland China.

\section{Consequences of Acculturative Stressors}

A large body of literature has demonstrated that acculturative stressors have detrimental effects on the mental and physical health of international students (e.g. Mak \& Neil, 2006; Jasinskaja-Lathi, Liebkind, Jaakkola, \& Reuter, 2006; Rosenthal, Russell, \& Thomson, 2006). First of all, for Chinese international students, poor English language 
proficiency was found to be a significant predictor of depressive symptoms (Mak \& Neil, 2006) and greater level of perceived acculturative stress (Yeh \& Inose, 2003). In contrast, English language proficiency and confidence was associated with better psychological well-being and greater life satisfaction (Liebkind \& Jasinskaja-Lahti, 2000; Perrucci \& $\mathrm{Hu}, 1995)$. Secondly, academic problems are associated with a wide range of negative emotions, such as disappointment, boredom, worry, and fear (Ramsay, Barker, \& Jones, 1999). Thirdly, a lack of social contacts within the host society was found to be related to a decline of emotional well-being and health problems such as anxiety, depression, somatic symptoms, and paranoia (Rogers \& Ward, 1993; Ying \& Liese, 1991; Sam \& Eide, 1991), and highly correlated with psychological distress (Spencer-Oatey \& Xiong, 2006). Finally, the perception of racial discrimination has been found to be associated with the erosion of positive affect and increase of depressive symptoms (Noh, Kaspar, \& Wickrama, 2007). Culture shock and cultural distance may contribute to a sense of alienation and isolation, which in turn may lead to depression (Bhugra, 2003; Lu, 1998). Unfulfilled expectations may lead to deep feelings of loss, disappointment, resentment, and sadness (Wong, Lam, Yan, \& Hung, 2004; Mori, 2000; Abbott, Wong, Williams, Au, \& Young, 1999).

\section{Existing Measurement of Acculturative Stress}

A number of instruments have been developed to measure acculturative stress among different groups of migrant populations. A review of the measurement of acculturative stress reveals several conceptual and methodological problems. First, the diversity of acculturative stress measurements suffers from conceptual confusion. The existing measurements can be grouped into two categories. One category consists of measurements of the impact of acculturative stress in terms of psychological and physical symptoms (e.g. Mishra et al., 1996; Chan, 2002), guided by the response-based definition of acculturative stress. The other category of measurements assesses acculturative stress as acculturative stressors (i.e. the sources of acculturative stress) or adjustment difficulties (e.g. Sandhu \& Asrabadi, 1994; Yang \& Clum, 1995), guided by the stimulus-based definition of acculturative stress. Thus, the existing measurements confuse the concept of acculturative stress with either acculturative stressor or the response of acculturative stress. It is necessary to differentiate these concepts. We agree with the process-oriented definition as it takes individual difference into consideration and emphasizes the role of person. Thus, we view stress as a process in which acculturative stressors have significant impact on stress response in terms of physical and psychological well-being.

Second, the majority of measurements lack evidence of validity, which is important to understand the factor structure and content of the construct. Some studies have reported criterion-related validity, but some criterion measurements have not been validated for the studied population (e.g. Yang \& Clum, 1995).

Finally, most acculturative stress measurements have been developed in Western countries. As the acculturation process can be influenced by the host culture (Berry, 2006a, 2006b) and cultural distance between the host culture and culture of origin (Pan, Wong, Joubert, \& Chan, 2008), these measurement are not necessarily applicable in Asian 
cultural contexts. Only one scale has been developed in an Asian context, which was designed to measure the acculturative stress experienced by young new arrivals in Hong Kong from mainland China (Chan, 2002). However, this scale measures psychological and physical symptoms caused by acculturative stressors. Thus, up to now, no scale has been available to assess the acculturative stressors experienced by Chinese migrants in a non-Western context.

\section{Purpose and Hypothesis of the Study}

The purpose of this study is to develop and validate a new scale that measures the acculturative hassles experienced by mainland Chinese university students in Hong Kong. We hypothesized that the acculturative stressor scores would be positively correlated with negative dimensions of psychological well-being (i.e. negative affect), and negatively correlated with positive dimensions of psychological well-being (i.e. positive affect and life satisfaction).

\section{METHOD}

\section{Scale Development}

Scale items were developed from in-depth interviews. Ethical approval was obtained from the Human Research Ethics Committee of The University of Hong Kong (HKU). A total of 14 mainland students, with an age range from 22 to 38 years, were recruited from HKU for the interview. Fifty percent $(n=7)$ were female and $50 \%(n=7)$ were male; $57 \%(n=8)$ were PhD students and $43 \%(n=6)$ were MPhil students; and $86 \%$ $(n=12)$ were single while $14 \%(n=2)$ were married. The informants were asked to elaborate on their adjustment difficulties and on any stressful situations they had encountered during their studies and living in Hong Kong. The interview was conducted in Mandarin and lasted approximately one hour. With the informant's approval, the interview was audio-taped and transcribed word-by-word. The qualitative data were open-coded, naming compared and categorized, using grounded theory as a guideline (Strauss \& Corbin, 1998). The analysis was conducted using NVivo 1.3. Acculturative hassles were grouped into eight categories (language difficulty, academic work, social interaction, cultural difference, perceived discrimination, financial problem, personal life and concern for future development, and family bond), which were subjected to an intercoder checking by a panel of experienced social work researchers at the Centre on Behavioral Health in the University of Hong Kong. A 100-item pool was generated for the scale, with 79 items developed from the eight categories of qualitative data analysis, and 21 other items adopted from relevant existing scales that measure the acculturative stressors experienced by international students (Sandhu \& Asrabadi, 1994; Yang \& Clum, 1995; Randall et al., 1998; Juarez, 1986). The 100-item was sent to two professors of acculturation for expert checking of the appropriateness and representativeness of the items for the construct. It was then sent out to eight mainland Chinese postgraduate students at HKU to check the comprehensibility of the items and to make sure they do not overlap. Eighty-four items were retained for item analysis following this procedure.

\section{Item Analysis}

The scale was further refined by testing the 84-item draft scale on a sample of 189 mainland Chinese postgraduate students in Hong Kong. The participants came from the University of Hong Kong (60\%), City University of Hong Kong (22\%), The Chinese University of Hong Kong (12\%), and Hong Kong University of Science and Technology $(6 \%)$. The sample consisted of a wide range of students in terms of their length of residence in Hong Kong: $28.6 \%$ of the participants had been in Hong Kong for less than one year, 20.1\% for one to two years, $30.7 \%$ for two to three years, and $20.1 \%$ for more than three years. The items were selected on the basis of the following criteria: (1) less than $60 \%$ of the participants responded "not at all" or "not applicable" on the item scale; (2) a reasonably low inter-item correlation $(r<.80)$ (Tso, Ng \& Chan, 2006); (3) a reasonably high corrected item-total correlation $(r>.40)$ (DeVellis, 2003); (4) a reasonably high 
recalculated corrected item-total correlation $(r>.40)($ DeVellis, 2003); and (5) the factor loading of each item in factor analysis higher than .40 (DeVellis, 2003). As a result, 18 items were excluded because more than $60 \%$ of the participants chose "not at all" or "not applicable" on the item scale. Thirty items with corrected item-total correlation lower than .40 were discarded. Sixteen more items were excluded because their corrected item-total correlations were lower than 0.40 after recalculated the correlations with the remained 36 items. Eventually, a total of 20 items were retained to form the Acculturative Hassles Scale for Chinese Students for further validation.

\section{Procedure and Sample}

A letter of invitation with a weblink to the online questionnaire was sent out to students, outlining the purpose and explaining the confidential and voluntary nature of the study. The letter was sent to mainland Chinese postgraduate students at six major universities in Hong Kong by webmail and posted on the Bulletin Board System (BBS) of the Mainland Chinese Students and Scholars Association of each of the universities. Hardcopies of the questionnaire with a consent form were distributed to the mailboxes at the student residential halls, and were forwarded by a snow-balling approach (Yegidis \& Weinbach, 2006). Hardcopies of the invitation letter were also posted on the notice boards of the student residence halls. Postage-paid return envelopes were attached to the questionnaire, and participants were asked to write down their university email addresses on the questionnaires to avoid receiving duplicate responses from the same respondent. The questionnaire was in Chinese. A souvenir was sent to the participants who completed the questionnaire. A total of 400 participants from the six universities in Hong Kong completed a valid questionnaire. The demographic characteristic of the participants are presented in Table 1.

\section{Measures}

Acculturative Hassles Scale for Chinese Students (AHSCS)

The 20-item AHSCS measures acculturative stressors that mainland Chinese students experience in their daily lives in Hong Kong. The participants were asked to indicate the degree to which they had experienced or were experiencing these stressors. The responses were rated on a 4-point Likert scale $(0=$ "not at all" or "not applicable," $1=$ "a little," $2=$ "moderate," and $3=$ "a lot"). The scores for each item were summated and divided by the total item number to arrive at the total scale score. A higher score indicates a higher level of acculturative stressors.

The following two scales were used as the criterion measurement to evaluate the convergent validity of the AHSCS.

Chinese Affect Scale (CAS; Hamid \& Cheng, 1996)

The Chinese Affect Scale was developed for Chinese people. It includes 20 items and two subscales: the Positive Affect Subscale (PAS) and the Negative Affect Subscale (NAS). The PAS includes 10 positive affect items, such as happy, peaceful, and content, and the NAS includes 10 negative affect items, such as sad, depressed, and helpless. The participants were asked to indicate how they had felt in the past month. All of the items were rated on a 5-point Likert scale (from $1=$ "very slightly" or "not at all" to 5 = "extremely"). The Cronbach's alpha coefficient was 0.83 for the NAS and 0.87 for the PAS for a student sample and 0.88 for the NAS and 0.90 for the PAS for an adult sample. The two-week test-retest reliability was 0.75 for the NAS and 0.78 for the PAS, and the one-month test-retest reliability was 0.71 for the NAS and 0.67 for the PAS. The NAS was found to be significantly positively correlated with neuroticism, negative self-appraisal, stress, and pessimism; and the PAS was found to be significantly positively correlated with extraversion, positive self-appraisal, optimism, and self-esteem (Hamid \& Cheng, 1996).

Satisfaction with Life Scale (Diener, Robert, Emmons, \& Griffin, 1985).

This scale measures global life satisfaction. It consists of five items rated on a 7-point Likert scale ( 1 = "totally disagree" to $7=$ "totally agree"). The total score ranges from 5 to 35 . High scores indicate high levels of global life satisfaction. The scale has been validated among the Chinese student population (Sachs, 2003). The Cronbach's alpha coefficient in this study was 0.91 and the Guttman split-half reliability was 0.86 . The average inter-item correlation was 0.67 with a range from 0.59 to 0.87 . 
Table 1. Demographic Information of the Participants

\begin{tabular}{|c|c|c|}
\hline Characteristic & $n$ & Percentage \\
\hline \multicolumn{3}{|l|}{ Gender } \\
\hline Male & 200 & 50.0 \\
\hline Female & 200 & 50.0 \\
\hline \multicolumn{3}{|l|}{ University } \\
\hline $\mathrm{HKU}^{1}$ & 181 & 45.3 \\
\hline City $U^{2}$ & 39 & 9.8 \\
\hline CUHK $^{3}$ & 94 & 23.5 \\
\hline HKUST $^{4}$ & 56 & 14.0 \\
\hline $\mathrm{HKBU}^{5}$ & 19 & 4.8 \\
\hline PolyU ${ }^{6}$ & 11 & 2.8 \\
\hline \multicolumn{3}{|c|}{ Duration of residence in Hong Kong } \\
\hline$\leq 0.5 \mathrm{y}$ & 155 & 38.8 \\
\hline $0.5 y-1 y$ & 27 & 6.8 \\
\hline $1 y-2 y$ & 79 & 19.8 \\
\hline $2 y-3 y$ & 72 & 18.0 \\
\hline$>3 y$ & 67 & 16.8 \\
\hline \multicolumn{3}{|l|}{ Level of education } \\
\hline $\mathrm{PhD}$ & 256 & 64.0 \\
\hline Master/MPhil & 144 & 36.0 \\
\hline \multicolumn{3}{|l|}{ Age (years) } \\
\hline$\leq 23$ & 72 & 18.0 \\
\hline $24-30$ & 269 & 67.0 \\
\hline $31-35$ & 50 & 12.5 \\
\hline $36-40$ & 6 & 1.5 \\
\hline$\geq 41$ & 3 & 0.8 \\
\hline \multicolumn{3}{|l|}{ Marital status } \\
\hline Single & 299 & 74.8 \\
\hline Married & 97 & 24.3 \\
\hline Other & 4 & 1.0 \\
\hline \multicolumn{3}{|l|}{ Religion } \\
\hline None & 357 & 89.3 \\
\hline Follow a religion & 43 & 1.7 \\
\hline Total & 400 & 100 \\
\hline
\end{tabular}

1. The University of Hong Kong; 2. City University of Hong Kong; 3. The Chinese University of Hong Kong; 4. Hong Kong University of Science and Technology; 5. Hong Kong Baptist University; 6. The Hong Kong Polytechnic University 


\section{RESULTS}

\section{Factor Structure}

Exploratory Factor Analysis (EFA) was conducted to identify the latent factor structure of the AHSCS. Before conducting EFA, we tested several statistical assumptions necessary for such an analysis. The Kaiser-Meyer-Olkin measure of sampling adequacy was 0.91 and Bartlett's test of sphericity was statistically significant $\left(x^{2}=3042.76\right.$, $d f=190, p<.001$ ), which satisfied the statistical assumptions for EFA (Ang \& Huan, 2006). The factors were expected to correlate with one another and perfect reliability was not assumed, so EFA was conducted with promax oblique rotation and extraction method of principal axis factoring (Fabrigar, Wegener, MacCallum, \& Strahan, 1999; Floyd \& Widaman, 1995). As suggested by Floyd and Widaman (1995) for a large sample of 300400 participants, items with a pattern coefficient greater than .40 were retained.

The principle of eigenvalue-over-one and scree plot test was used to determine the number of factor. EFA suggested a four-factor solution with 17 items (i.e. the final version of the AHSCS). Three items were excluded because their pattern coefficients were less than .40 . The retained 17 items accounted for $46.26 \%$ of the total variance. The results of EFA are presented in Table 2, along with the corrected item-total correlation, means, and standard deviations for each item. The Chinese version of the 17-item AHSCS is presented in Appendix 1. Factor 1 consisted of four items that were related to a deficiency in English language ability, and was named Language Deficiency. Factor 2 comprised five items that involved academic stressors encountered during study at the host universities, and was named Academic Work. Factor 3 consisted of four items that pertained to the acculturative stressor caused by the cultural difference between Hong Kong and mainland China, and was named Cultural Difference. Factor 4 included four items that pertained to the issues of interpersonal interactions with others in the new environment, and was named Social Interaction. Correlations between these factors were in the moderate range $\left(r_{12}=.73, r_{13}=.56, r_{14}=.31, r_{23}=.64, r_{24}=.32, r_{34}=.37\right)$, which indicated that they overlapped to some degree but made separate contributions to the total score. The means of each item ranged from 0.62 to 1.75 on a 4-point Likert scale $(0-3)$. The standard deviations of the items were in the range of 0.82 to 1.06 , which indicated high discrimination.

\section{Internal Consistency Reliability}

The internal consistency reliability of the AHSCS was satisfactory. For the total score of the AHSCS, the Cronbach's alpha coefficient was .88 and Guttman split-half reliability was .86 . The Cronbach's alpha coefficient of the four subscales of the AHSCS was .81 (Factor 1 Language Deficiency), .74 (Factor 2 Academic Work), .76 (Factor 3 Cultural Difference), and .74 (Factor 4 Social Interaction). The Guttman split-half reliability of the four subscales was .79 (Factor 1 Language Deficiency), .71 (Factor 2 Academic Work), .76 (Factor 3 Cultural Difference) and .76 (Factor 4 Social Interaction). The average inter-item correlation for the total score was .31 with a range of .11 to .56 ; for the four subscale scores, the range was from .37 to .51 . In addition, the corrected item- 
Table 2. Rotated Factor Pattern Coefficients for the AHSCS, Corrected Item-total Correlations, Means, and Standard Deviations

\begin{tabular}{|c|c|c|c|c|c|c|c|}
\hline Item & Factor 1 & Factor 2 & Factor 3 & Factor 4 & $r$ & $M$ & $S D$ \\
\hline \multicolumn{8}{|l|}{ Factor 1: Language Deficiency (4) } \\
\hline 3. I am not able to express my ideas in English fluently. & .84 & -.11 & -.11 & .13 & .54 & 1.62 & 0.97 \\
\hline 12. I dare not speak in English in a class or seminar. & .75 & -.21 & .14 & .08 & .56 & 1.17 & 0.96 \\
\hline 16. I do not have a sufficient English vocabulary. & .67 & .18 & -.10 & -.04 & 0.53 & 1.42 & 0.91 \\
\hline 8. I am not accustomed to the English way of thinking. & .61 & .07 & .01 & .13 & .60 & 1.32 & 0.95 \\
\hline \multicolumn{8}{|l|}{ Factor 2: Academic Work (5) } \\
\hline $\begin{array}{l}\text { 4. Publishing academic papers in English is difficult } \\
\text { for me. }\end{array}$ & -.05 & .82 & -.22 & .07 & .47 & 1.57 & 0.93 \\
\hline $\begin{array}{l}\text { 6. It is difficult for me to reach my supervisor's } \\
\text { expectations on my study. }\end{array}$ & .04 & .57 & .04 & .07 & .58 & 1.06 & 0.91 \\
\hline $\begin{array}{l}\text { 15. I feel pressured when making comparison with } \\
\text { fellow students. }\end{array}$ & .00 & .52 & .14 & .08 & .58 & 0.95 & 0.87 \\
\hline $\begin{array}{l}\text { 1. When I first arrived at Hong Kong, I did not know } \\
\text { how to start my study. }\end{array}$ & -.11 & .52 & .05 & .07 & .41 & 1.17 & 0.92 \\
\hline 10. I am worried whether I can graduate as scheduled. & -.02 & .47 & .10 & .09 & .50 & 1.03 & 0.98 \\
\hline \multicolumn{8}{|l|}{ Factor 3: Cultural Difference (4) } \\
\hline $\begin{array}{l}\text { 11. There are great cultural differences between Hong } \\
\text { Kong and the Mainland which make me feel } \\
\text { maladaptive. }\end{array}$ & -.18 & .00 & .81 & .10 & .53 & 0.62 & 0.82 \\
\hline $\begin{array}{l}\text { 13. There is huge gap between my expectation about } \\
\text { Hong Kong and the actual situation. }\end{array}$ & .03 & -.18 & .74 & .08 & .47 & 0.75 & 0.82 \\
\hline $\begin{array}{l}\text { 17. I feel uncomfortable when I am trying to adapt to a } \\
\text { new culture and values }\end{array}$ & .02 & .05 & .59 & .14 & .58 & 0.69 & 0.79 \\
\hline $\begin{array}{l}\text { 9. I worry that Hong Kong people will discriminate } \\
\text { against people from the Mainland. }\end{array}$ & .07 & .03 & .41 & .15 & .48 & 0.88 & 0.87 \\
\hline \multicolumn{8}{|l|}{ Factor 4: Social Interaction (4) } \\
\hline $\begin{array}{l}\text { 7. It is difficult for me to integrate into the social circle } \\
\text { of local people. My relationships with the locals } \\
\text { are general working relationships. }\end{array}$ & .18 & .02 & -.06 & .70 & .53 & 1.63 & 1.03 \\
\hline $\begin{array}{l}\text { 5. My social space in Hong Kong is very small. I am } \\
\text { either at work or at home. }\end{array}$ & .03 & .09 & .08 & .63 & .54 & 1.75 & 1.00 \\
\hline $\begin{array}{l}\text { 14. It is very difficult for me to integrate into the local } \\
\text { culture in Hong Kong. }\end{array}$ & -.03 & .08 & .28 & .46 & .53 & 1.30 & 0.93 \\
\hline 2. I do not have a new social network in Hong Kong. & .00 & .07 & .13 & .40 & .40 & 1.57 & 1.06 \\
\hline
\end{tabular}

Note: 1. Extraction method: principle Axis Factoring.

2. Rotation method: promax with Kaiser normalization.

3. Pattern coefficients greater than .40 are in bold and italicized.

4. AHSCS $=$ Chinese Acculturative Stressor Scale; $r=$ corrected item-total correlation. 
total correlations for each item were all in the moderate range $(r=.40$ to $r=.60)$ (Table 2). The Pearson correlations of the AHSCS total score and its four sub-scale scores were as follows: Language Deficiency $(r=.78)$, Social Interaction $(r=.77)$, Academic Work $(r=.82)$, and Cultural Difference $(r=.76)$. These correlation coefficients were all at a statistically significant level of $p<.001$ with a sample size of 400 .

\section{Convergent Validity}

Convergent validity was assessed by examining the associations with the criterion measurements that were empirically found to be related to acculturative stressors. It was expected that the AHSCS score would show a positive association with positive dimensions of psychological well-being (i.e. positive affect and life satisfaction) and a negative association with negative dimensions of psychological well-being (i.e. negative affect). The correlational relationships between the AHSCS and criterion measurements were all in the expected direction. The AHSCS total score and the scores of the four subscales had a statistically significant positive correlation with negative affect $(r=.44$, $\left.p<.001 ; r_{1}=.30, p<.001 ; r_{2}=.43, p<.001 ; r_{3}=.37, p<.001 ; r_{4}=.28, p<.001\right)$ and a statistically significant negative correlation with positive affect $\left(r=-.31, p<.001 ; r_{1}=-.17\right.$, $\left.p<.001 ; r_{2}=-.25, p<.001 ; r_{3}=-.26, p<.001 ; r_{4}=-.28, p<.001\right)$ and life satisfaction $\left(r=-.28, p<.001 ; r_{1}=-.19, p<.001 ; r_{2}=-.24, p<.001 ; r_{3}=-.22, p<.001 ; r_{4}=-.24\right.$, $p<.001)$. These results demonstrate some initial evidence of good convergent validity of the AHSCS.

\section{DISCUSSION}

The purpose of this study was to develop a self-report scale to measure acculturative hassles experienced by Chinese students within an Asian context, and to validate its scores in a sample of mainland university students in Hong Kong. The item pool was created from semi-structured interviews to tap a wide variety of adjustment problems experienced by mainland university students in their acculturation to Hong Kong. Item analysis and factor analysis retained 17 items with four subscales. Results suggested that the AHSCS provided internally consistent and reliable scores. Initial evidence of convergent validity was also reported.

This study identified four factors of acculturative hassles experienced by Chinese students in an Asian context: Language Deficiency, Academic Work, Cultural Difference, and Social Interaction. These four factors were believed to describe the major categories of daily hassles experienced by mainland Chinese students living in Hong Kong. First, language difficulty is the major adjustment issue faced by mainland students. In the universities in Hong Kong, English is the language of instruction, and students are required to take courses and write their thesis in English. Although most mainland students learn English as a second language before they come to Hong Kong, they still find that they are not proficient enough to use English in their studies and daily life, especially listening and speaking. Second, the higher educational system in Hong Kong is 
different from that of mainland China. As postgraduate students, students are required to complete a $\mathrm{PhD}$ or MPhil thesis within a defined period; whether they can find a proper research topic or focus for their study, publish papers in international journals, and graduate on time become major concerns for those mainland students who were trained in a course-based educational system in China. Third, although Hong Kong is currently a part of China, there are cultural differences between Hong Kong and mainland China due to Hong Kong's unique history as a British colony for over 150 years. The impact of Western culture is deeply rooted in Hong Kong society. Mainland students have to learn how to behave and what to expect in a new cultural and value system which differs from their own. Finally, migration involves separation from one's social network and sacrifice of familiarity with one's previous lifestyle (Lou \& Chan, 1998). Re-establishing a new social network in a new environment may be a big challenge for most sojourners.

The four factors of acculturative hassles experienced by mainland university students in Hong Kong are consistent with the previous findings on Chinese international students in Western countries and mainland young arrivals living in Hong Kong (Yang \& Clum, 1995; Rodriguez, Myers, Mira, Flores, \& Garcia-Hernandez, 2002; Sandhu \& Asrabadi, 1994; Chan, 2002; Wong, 1997). However, two other domains of acculturative stressors which were reported in most Western measures did not appear in the AHSCS. One is perceived discrimination (e.g. Sandhu \& Asrabadi, 1994), and the other is financial concern (e.g. Yang \& Clum, 1995). It may be related to the unique context of Hong Kong. Financial difficulty is not a major concern for mainland students as all the Hong Kong universities offer full scholarships to all full-time research students during their study period, which can cover their tuition fees and living expenses. In addition, since the handover of Hong Kong to China in 1997, an interdependent relationship involving frequent communication has been developed between the two parties, and mutual understanding between their people has gradually been established. In fact, most mainland migrants experience positive attitudes rather than discrimination from the local people in Hong Kong (Hong, et al., 2006; Chan, 1998).

This study has provided some initial evidence of the convergent validity of the AHSCS. The hypothesized relationships between the AHSCS score and mental health outcome measures were confirmed. Consistent with previous findings, the AHSCS score showed an expected a positive association with negative affect and negative associations with positive affect and life satisfaction. Although the correlational coefficients were not high enough, they were all in the expected direction with a statistical significance level of .001.

This study has several limitations. First, since the AHSCS was developed for mainland Chinese university students in Hong Kong, its application to Chinese international students living outside Hong Kong needs further investigation and validation. As a largest source of international students on a worldwide basis, future studies should validate the AHSCS among Chinese international students in other countries. Second, confirmatory factor analysis should be performed in future research to test the stability of the factor structure of the AHSCS. Finally, the stability of the AHSCS over time has not been tested in this study. Future studies should investigate the test-retest reliability of the AHSCS. 
Despite the above limitations, this study has provided an indigenous instrument for acculturation research in an Asian context, especially research focused on the Chinese student population. Acculturation is cultural-specific with its process influenced by the characteristics of the host society and the society of origin (Berry, 2006b). With the increasing number of migrants within Asian countries, the development of indigenous measures would enhance research on migration and mental health in Asia.

\section{REFERENCES}

Abbott, M. W., Wong, S., Williams, M., Au, M., \& Young, W. 1999. Chinese migrants' mental health and adjustment to life in New Zealand. Australian and New Zealand Journal of Psychiatry, 33, 13-18.

Aldwin, C. M. 1994. Stress, coping and development: An integrative perspective. New York: Guilford.

Ang, R. P., \& Huan, V. S. 2006. Academic expectation stress inventory: Development, factor analysis, reliability, and validity. Educational and Psychological Measurement, 66, 522-539.

Berry, J. W. 1990. Psychology of acculturation. In Nebraska symposium on motivation (Vol. 37, pp. 201234). Nebraska: the University of Nabraska Press.

Berry, J. W. 2006a. Acculturative stress. In P. T. P. Wong \& L. C. J. Wong (Eds.), Handbook of multicultural perspective on stress and coping (pp. 287-298). New York: Springer.

Berry, J. W. 2006b. Stress perspectives on acculturation. In D. L. Sam \& J. W. Berry (Eds.), The Cambridge handbook of acculturation (pp. 43-57). Cambridge: Cambridge University Press.

Bhugra, D. 2003. Migration and depression. Acta Psychiatric Scandinavica, 108(Suppl. 418), 67-72.

Chan, J. 1999. A survey study on the psychological adaptation of newly arrived students from mainland china. Hong Kong: Aberdeen Kai-Fong Welfare Association Social Service Centre.

Chan, K. H. 1998. Attitudes and social integration of the newly immigrated and the local children. In J. Chan (Ed.), Psychological adaptation of children and youth newly arrived in Hong Kong from mainland china: Research, theory and practice (pp. 107-123). Hong Kong: Aberdeen Kai-fong Welfare Association Social Service Centre.

Chan, M. C., Ip, K. Y., \& Yuen, M. T. 1997. Adaptation and needs of young new arrivals from mainland china in the Shamsuipo district (rev. Ed.) (in Chinese). Hong Kong: Sham Siu Po District Board.

Chan, M. C., \& Ma, K. 1999. A research report on new arrival families' need and adaptation. Hong Kong: Sham Sui Po District Board.

Chan, R. M. C. 2002. Acculturation of young new arrivals from mainland china to Hong Kong. Unpublished Ph.D. thesis, The Chinese University of Hong Kong, Hong Kong.

Cox, T. 1978. Stress. London: MaCmillan Press.

DeVellis, B. F. 2003. Scale development: Theory and application (2th ed.). Thousand Oaks: Sage Publications.

Diener, E., Robert, A., Emmons, R. J. L., \& Griffin, S. 1985. The satisfaction with life scale. Journal of Personality Assessment, 49, 71-75.

Fabrigar, L. R., Wegener, D. T., MacCallum, R. C., \& Strahan, E. J. 1999. Evaluating the use of exploratory factor analysis in psychological research. Psychological Assessment, 4, 272-299.

Floyd, F. J., \& Widaman, K. F. 1995. Factor analysis in the development and refinement of clinical assessment instruments. Psychological Assessment, 7, 286-299.

Fung. 2000. Friendship formation of new arrival adolescent. Unpublished Master's thesis, University of Hong Kong, Hong Kong.

Hamid, P. N., \& Cheng, S. T. 1996. The development and validation of an index of emotional disposition and mood state: The Chinese Affect Scale. Educational and Psychological Measurement, 56, 995-1014.

Ho, E., Holmes, P., \& Cooper, J. 2004. Review and evaluation of international literature on managing cultural diversity in the classroom: Report for Ministry of Education and Education New Zealand, Wellington.

Hong, Y. Y., Liao, H. Y., Chan, G., Wong, R. Y. M., Chiu, C. Y., Ip, G. W. M., et al. 2006. Temporal causal 
links between outgroup attitudes and social categorization: The case of Hong Kong 1997 transition. Group process and Intergroup Relations, 9, 265-288.

Hong Kong Federation of Youth Groups. 1995. The population poser: How do young new arrivals from mainland china adapt? Hong Kong: Hong Kong Federation of Youth Groups.

Hong Kong Federation of Youth Groups. 1997. Research on adaptation of young arrivals from mainland china. Hong Kong: Hong Kong Federation of Youth Groups Hung Hum Youth Centre.

Hsu, L. R., Hailey, B. J., \& Range, L. M. 1987. Cultural and emotional components of loneliness and depression. The Journal of Psychology, 121, 61-70.

ITIM-International. 2003a. Geert hofstede cultural dimensions-china. Available online at: http:// www.Geert-hofstede.Com/hofstede_china.Shtml. (accessed on 09/01/2008).

ITIM-International. 2003b. Geert hofstede cultural dimensions-china. Available online at: http:// www.Geert-hofstede.Com/hofstede_hong_kong.Shtml. (accessed on 09/01/2008).

Jasinskaja-Lahti, I., Liebkind, K., Jaakkola, M., \& Reuter, A. 2006. Perceived discrimination, social support network, and psychological well-being among three immigrant groups. Journal of Cross-cultural Psychology, 37, 293-311.

Jiang, X. Q. 2002. Hong Kong's university see the mainland as fertile ground for recruiting students. Chronicle of Higher Education, 48, A41-42.

Joiner Jr., T. E., \& Walker, R. L. 2002. Construct validity of a measure of acculturative stress in African Americans. Psychological Assessment, 14, 462-466.

Juarez, A. H. 1986. Development and validation of an instrument to measure stress in foreign students. Unpublished Ph.D. thesis, Brigham Young University.

Kanner, A. D., Coyne, J. C., Schaefer, C., \& Lazarus, R. S. 1981. Comparison of two modes of stress measurement: Daily hassles and uplifts versus major life event. Journal of Behavioral Medicine, 4, 1-39.

Kim, Y. Y. 2005. Inquiry in intercultural and development communication. Journal of Communication, 55, 554-577.

Lam, K., \& Liu, P. 1993. Are immigrants assimilating better now than a decade ago? Hong Kong: Hong Kong Institute of Asia-Pacific Studies.

Lay, C., \& Nguyen, T. 1998. The role of acculturation-related and acculturation non-specific daily hassles: Vietnamese-Canadian students and psychological distress. Canadian Journal of Behavioral Science, 30, 172-181.

Lazarus, R. S., \& Folkman, S. 1984. Stress, appraisal and coping. New York: Springer Publishing Company, Inc.

Lee, F. W. L., \& Chen, T. K. K. 2005. Service needs of young new arrivals from mainland china to Hong Kong. Asia Pacific Journal of Social Work and Development, 15, 55-74.

Liebkind, K., \& Jasinskaja-Lahti, I. 2000. Acculturation and psychological well-being among immigrant adolescents in Finland: A comparative study of adolescents from different cultural backgrounds. Journal of Adolescent Research, 15, 446-469.

Lin, L. 1998. Chinese graduate students perception of their adjustment experiences at the University of Pittsburgh. Unpublished Ph. D. thesis, University of Pittsburgh.

Lo, K. T., Wan, A., \& Chung, L. 1998. A survey study on the psychological adaptation of newly arrived students from mainland china. In J. Chan (Ed.), Psychological adaptation of children and youth newly arrived in Hong Kong from mainland china: Research, theory and practice (pp. 000-000). Hong Kong: Aberdeen Kai-fong Welfare Association Social Service Centre.

Lou, V., \& Chan, C. 1998. Stress and social adaptation of immigrant adolescents from mainland china: A cultural cooperative model. In J. Chan (Ed.), Psychological adaptation of children and youth newly arrived in Hong Kong from mainland china: Research, theory and practice (pp. 145-158). Hong Kong: Aberdeen Kai-fong Welfare Association Social Service Centre.

Lu, D. 1998. Facing dilemmas: Chinese students in the united states:1979-1989. Unpublished Ph.D. thesis, University of Oregon.

Lu, L. 1990. Adaptation to British universities: Homesickness and mental health of Chinese students. Counselling Psychology Quarterly, 3, 225-233.

Mak, A. S., \& Barker, M. C. 2006. Social integration: Strategies to foster migrants' effective participation in a group. Prevention, protection and promotion: Proceedings of the Second International Asian Health and Wellbeing Conference, Nov. 13-14, (pp. 147-155). Auckland, New Zealand: University of Auckland.

Mak, A. S., \& Neil, A. L. 2006. How does social contact with locals impact on mental health: Chinese 
background international students in Australia. Prevention, protection and promotion: Proceedings of the Second International Asian Health and Wellbeing Conference, Nov. 13-14, (pp. 124-132). Auckland, New Zealand: University of Auckland.

Mishra, R. C., Sinha, D., \& Berry, J. W. 1996. Ecology, acculturation and psychological adaptation: A study of adivasis in Bihar. New Delhi: Sage Publications.

Mori, S. 2000. Addressing the mental health concerns of international students. Journal of Counseling and Development, 78, 137-144.

Noh, S., Kaspar, V., \& Wickrama, K. A. S. 2007. Overt and subtle racial discrimination and mental health: Preliminary findings for Korean immigrants. American Journal of Public Health, 97, 1269-1274.

Pan, J. Y., Wong, D. F. K., Joubert, L., \& Chan, C. L. W. 2008. The protective function of meaning of life on life satisfaction among Chinese international students in Australia and Hong Kong: A cross-cultural comparative study. Journal of American College health, 57, 221-231.

Perez, M., Voelz, Z. R., Pettit, J. W., \& Joiner, T. 2002. The role of acculturative stress and body dissatisfaction in predicting bulimic symptomatology across ethnic groups. International Journal of Eating Disorders, 31, 442-452.

Perrucci, R., \& Hu, H. 1995. Satisfaction with social and educational experiences among international graduate students. Research in Higher Education, 36, 491-508.

Ramsay, S., Barker, M., \& Jones, E. 1999. Academic adjustment and learning processes: A comparison of international and local students in first-year university. Higher Education Research and Development, 18, 129-144.

Randall, M., Naka, K., Yamamoto, K., Nakamoto, H., Arakaki, H., \& Ogura, C. 1998. Assessment of psychological stressors and maladjustment among foreign students of the University of Ryukyus. Psychiatry and Clinical Neurosciences, 52, 289-298.

Rodriguez, N., Myers, H. F., Mira, C. B., Flores, T., \& Garcia-Hernandez, L. 2002. Development of the multidimensional acculturative stress inventory for adults of mexican origin. Psychological Assessment, 14, 451-461.

Rogers, J., \& Ward, C. 1993. Expectation-experience discrepancies and psychological adjustment during cross-cultural reentry. International Journal of Intercultural Relations, 17, 185-196.

Rosenthal, D. A., Russell, V. J., \& Thomson, G. D. 2006. A growing experience: The health and well-being of international students at the University of Melbourne. Melbourne: The University of Melbourne.

Rowlison, R., \& Felner, R. 1988. Major life events, hassles, and adaptation in adolescence: Confounding in the conceptualization and measurement of life events revisited. Journal of Personality and Social Psychology, 55, 432-444.

Sachs, J. 2003. Validation of the satisfaction with life scale in a sample of Hong Kong university students. Psychologia, 46, 225-234.

Sam, D. L., \& Eide, R. 1991. Survey of mental health of foreign students. Scandinavian journal of psychology, 32, 22-30.

Sandu, D. S., \& Asrabadi, B. R. 1994. Development of an acculturative stress for international students: Preliminary findings. Psychological Reports, 75, 435-448.

Selye, H. 1982. History and present status of the stress concept. In L. Goldberger \& S. Breznitz (Eds.), Handbook of stress: Theoretical and clinical aspects (pp. 7-20). New York: The Free Press.

Sheh, S. 1994. Adjustment of Hong Kong students in the University of Alberta. Unpublished Ph.D. thesis, University of Alberta, Canada.

Shuval, J. T. 1982. Migration ans stress. In L. Goldberger \& S. Breznitz (Eds.), Handbook of stress: Theoretical and clinical aspects (pp. 677-694). New York: The Free Press.

Sobrun-Maharaj, A. 2006. Social acceptance and mental well-being of Asians in New Zealand. Prevention, protection and promotion: Proceedings of the Second International Asian Health and Wellbeing Conference, Nov. 13-14, 133-146.

Spencer-Oatey, H., \& Xiong, Z. 2006. Chinese students' psychological and sociocultural adjustments to Britain: An empirical study. Language, Culture and Curriculum, 19, 37-53.

Strauss, A., \& Corbin, J. 1998. Basics of qualitative research: Techniques and procedures for developing grounded theory. Thousand Oaks: Sage Publications.

Sun, W., \& Chen, G. M. 1997. Dimensions of difficulties mainland Chinese students encounter in the united states. (REIC accession number: ED408635). 
Swager, M. A., \& Ellis, M. V. 2003. Crossing the distance: Adjustment of Taiwanese graduate students in the united states. Journal of Counseling Psychology, 50, 420-437.

Tso, I. F., Ng, S. M., \& Chan, C. L. W. 2006. The development and validation of the concise outpatient department user satisfaction scale. International Journal for Quality in Health, 18, 275-280.

University Grants Committee in Hong Kong. 2008. Accessed at http://www.Ugc.Edu.Hk/eng/ugc/index.Htm on $13 / 02 / 2008$.

Ward, C. 2006a. International students: Interpersonal, institutional and community impacts. Updates of the 200 literature review. Reports for the ministry of education. Wellington, New Zealand: Centre for Applied Cross-cultural Research, Victoria, University of Wellington.

Ward, C. 2006b. Acculturation, social inclusion and psychological well-being of Asian migrants in New Zealand. Prevention, protection and promotion: Proceedings of the Second International Asian Health and Wellbeing Conference, Nov. 13-14, 116-123.

Ward, C., \& Masgoret, A. M. 2004. The experience of international students in New Zealand: Report on the results of the national survey. Wellington, New Zealand: Ministry of Education.

Williams, F. C. 2003. Concerns of newly arrived immigrant students: Implications for school counselors. Professional School Counseling, 7, 9-15.

Wong, D. F. K., Lam, D., Yan, P., \& Hung, M. 2004. The impacts of acculturative stress and social competence on the mental health of mainland Chinese immigrant youth in Hong Kong. British Journal of Social Work, 34, 1009-1024.

Wong, K. F. 1997. A study of psychological stressor, coping and mental health of mainland Chinese immigrants: Their first two years experience in Hong Kong. Unpublished Ph.D. thesis, La Trobe University, Melbourne, Australia.

$\mathrm{Xu}$, J. 2002. Chinese students' adaptation to leaning in an American university: A multiple case study. Unpublished Ph.D. thesis, University of Nebraska.

Yang, B., \& Clum, G. A. 1995. Measures of life stress and social support specific to an Asian student population. Journal of Psychopathology and Behavioral Assessment, 17, 51-67.

Yegidis, B. L., \& Weinbach, R. W. 2006. Research methods for social workers (5th ed.). Boston: Pearson/ Allyn \& Bacon.

Yeh, C., \& Inose, M. 2003. International students' reported English fluency, social support satisfaction, and social connectedness as predictors of acculturative stress. Counseling Psychology Quarterly, 16, 15-28.

Ying, Y. W., \& Liese, L. H. 1991. Emotional well-being of Taiwan students in the U.S.: An examination of pre-to post-arrival differential. International Journal of Intercultural Relations, 15, 345-366.

林静雯. 2000. 新来港人士家庭工作计划: 10/1998 至 3/2000 中期检讨报告. 香港: 香港小童群益会新来港人士家庭 工作计划: 香港中文大学社会工作学系. 


\section{Appendix 1}

The Chinese version of the 17-item Acculturative Hassles Scale for Chinese Students (AHSCS)

中国学生 跨文化适应压力量表

以下的描述是有关内地学生在适应香港的生活和学习的过程中可能会遇到的困难或压力情境, 请判断你 在多大程度上正在或曾经经历过这些困难, 请在符合你实际情况的选项上打钩。

$\begin{array}{cccc}0 & 1 & 2 & 3 \\ \text { 没有或不适用 } & \text { 有点 } & \text { 适中 } & \text { 很多 }\end{array}$

1. 刚来香港的时候, 我不知道该从哪里着手开始我的学习。

2. 在香港我没有新的社会网络。

3. 我不能很自如地用英语表达自己的想法。

4. 对我来说发表学术论文有很大压力。

5. 在香港, 我的社会空间很小, 不是在办公室, 就是在家里。

6. 我觉得在学业上我很难达到导师的期望。

7. 我很难融入到香港人的生活圈子里去, 我和香港人的关系都是 一般的工作关系。

8. 我不习惯英文的思维方式。

9. 我担心香港人会歧视内地人。

10. 我经常担心自己能否按时毕业。

11. 香港和内地的文化差异很大, 这让我觉得不太适应。

12. 上课或参加研讨会的时候我不敢用英语发言。

13. 我对香港的期望和实际情况有很大的差距。

14. 我很难真正融入到香港本地的文化中去。

15. 和周围的同学相比我会觉得有压力。

16. 我的英语词汇量不足, 要用的时候总觉得不够用。

17. 我在适应新的文化和价值观的时候觉得不舒服。

$\begin{array}{llll}0 & 1 & 2 & 3 \\ 0 & 1 & 2 & 3 \\ 0 & 1 & 2 & 3 \\ 0 & 1 & 2 & 3 \\ 0 & 1 & 2 & 3 \\ 0 & 1 & 2 & 3 \\ 0 & 1 & 2 & 3 \\ 0 & 1 & 2 & 3 \\ 0 & 1 & 2 & 3 \\ 0 & 1 & 2 & 3 \\ 0 & 1 & 2 & 3 \\ 0 & 1 & 2 & 3 \\ 0 & 1 & 2 & 3 \\ 0 & 1 & 2 & 3 \\ 0 & 1 & 2 & 3 \\ 0 & 1 & 2 & 3 \\ 0 & 1 & 2 & 3\end{array}$

